\title{
RNA sensing via LGP2 is essential for the induction of a type I IFN response in ADAR1 deficiency
}

Jorn E. Stok ${ }^{*},{ }^{1}$, Timo Oosenbrug ${ }^{*}{ }^{1}$, Laurens R. ter Haar ${ }^{1}$, Dennis Gravekamp ${ }^{1}$, Christian P. Bromley $^{2}$, Santiago Zelenay ${ }^{2}$, Caetano Reis e Sousa ${ }^{3}$, Annemarthe G. van der Veen ${ }^{\#, ~}$

Affiliations:

${ }^{1}$ Leiden University Medical Centre, Department of Immunology, Leiden, The Netherlands

${ }^{2}$ Cancer Research UK Manchester Institute, The University of Manchester, Alderley Park, United Kingdom

${ }^{3}$ The Francis Crick Institute, Immunobiology Laboratory, London, United Kingdom

* These authors contributed equally to this work.

\#Corresponding author. Tel: +31 526 2908. Email: A.G.van_der_Veen@lumc.nl

Keywords: innate immunity, RIG-I-like receptor family, self RNA sensing, RNA editing, type I interferon, autoinflammation

Subject categories: Immunology; RNA Biology

Running title: LGP2 senses self RNA in ADAR1 deficiency 


\section{Abstract}

RNA editing by the enzyme Adenosine Deaminase Acting on RNA 1 (ADAR1) is an important mechanism by which cells avoid innate immune responses to some endogenous RNAs. In

5 ADAR1-deficient cells, unedited self RNAs can form base-paired structures that resemble

6 viral RNAs and inadvertently activate antiviral innate immune pathways that lead to the

7 induction of type I interferon (IFN). Rare mutations in ADAR1 cause Aicardi-Goutières

8 Syndrome (AGS), a severe childhood autoinflammatory syndrome that is characterized by

9 chronic and excessive type I IFN production and developmental delay. Conversely, ADAR1 dysfunction and consequent type I IFN production helps restrict tumor growth and potentiates the activity of some chemotherapy drugs. Induction of type I IFN in ADAR1deficient cells is thought to be due to triggering of the cytosolic RIG-I-like receptor (RLR), MDA5, by unedited self RNAs. Here, we show that another RLR, LGP2, also has an essential role. We demonstrate that ADAR1-deficient human cells fail to mount a type I IFN response in the absence of LGP2 and this involves the canonical function of LGP2 as an RNA sensor and facilitator of MDA5-dependent signaling. Further, we show that the sensitivity of tumor cells to ADAR1 loss requires the presence of LGP2. Finally, we find that type I IFN induction in tumor cells depleted of ADAR1 and treated with some chemotherapeutics is fully dependent on the expression of LGP2. These findings highlight a central role for LGP2 in self RNA sensing with important clinical implications for the treatment of AGS as well as for the potential application of ADAR1-directed anti-tumor therapy. 


\section{Introduction}

Receptors of the innate immune system continuously sample the intra- and extracellular environment for signs of an ongoing infection. Viral infections can be detected through the presence of viral nucleic acids in the cytosol of infected cells (Rehwinkel \& Gack, 2020;

Goubau et al, 2013). Upon encountering viral DNA or RNA, cytosolic nucleic acid sensors, most notably cGAS or RIG-I-like receptors (RLRs), respectively, initiate an antiviral type I interferon (IFN) response (Ablasser \& Hur, 2020; Rehwinkel \& Gack, 2020). While a type I IFN response is important for defense against viral infections, its inadvertent activation by self-derived nucleic acids induces a sterile inflammatory response that causes immunopathology (Schlee \& Hartmann, 2016). Cellular mechanisms that ensure the discrimination between foreign and endogenous nucleic acids are therefore critical to avoid autoinflammation (Schlee \& Hartmann, 2016). constitutes an important mechanism by which cells ensure self/non-self RNA discrimination

41 (Heraud-Farlow \& Walkley, 2016; Quin et al, 2021; Uggenti et al, 2019). Through modification of endogenous RNA, ADAR1 prevents the activation of cytosolic RNA sensors, including RLRs, by cellular RNA molecules and the unwanted induction of an antiviral type I IFN response (Heraud-Farlow \& Walkley, 2016; Uggenti et al, 2019; Quin et al, 2021). The importance of ADAR1 is highlighted by the severe consequences of ADAR1 mutations in patients with Aicardi-Goutières Syndrome (AGS) (Rice et al, 2012; Rodero \& Crow, 2016). This rare genetic disorder belongs to the spectrum of type I interferonopathies, which are 
of an infection (Rodero \& Crow, 2016). The autoinflammatory condition that arises from

inherited ADAR1 mutations leads to severe (neuro)pathological features (Rice et al, 2017;

Livingston \& Crow, 2016). Notably, ADAR1 has also emerged as an attractive target for novel immunotherapeutic approaches in cancer (Bhate et al, 2019). A subset of tumor cells is sensitive to growth arrest upon knockdown or knockout of ADAR1, both in vivo and in vitro (Ishizuka et al, 2019; Gannon et al, 2018; Liu et al, 2019). In addition, intra-tumoral loss of

ADAR1 increases sensitivity to treatment with immune checkpoint inhibitors and overcomes resistance to such inhibitors in vivo (Ishizuka et al, 2019). Finally, depletion of ADAR1 in cancer cells potentiates the efficacy of epigenetic therapy and increases type I IFN induction (Mehdipour et al, 2020). Understanding the precise mechanism by which ADAR1 (dys)function impacts on innate immunity is therefore essential to better understand its disease-causing role in interferonopathies as well as its therapeutic potential in cancer. ADAR1 exists as two isoforms. The nuclear p110 isoform is constitutively expressed, while the $\mathrm{p} 150$ isoform is induced by type I IFN receptor signaling and resides primarily in the cytoplasm (Heraud-Farlow \& Walkley, 2016; Quin et al, 2021). Both isoforms act on base-paired RNA to deaminate adenosines and convert them to inosines. A-to-I editing is amongst the most widespread base modifications in mammals. Besides site-specific A-to-I editing, which can alter open reading frames, miRNA seed sequences or RNA splice sites, there is also highly promiscuous and abundant editing of base-paired RNAs with long regions of high complementarity such as transcripts spanning inverted repeat Alu (IR-Alu) elements (Eisenberg \& Levanon, 2018). Without editing, such base-paired structures would resemble double-stranded RNAs (dsRNAs) that are abundantly found in cells infected with some viruses. Unedited self RNA molecules are therefore prone to activate antiviral innate immune mechanisms, such as protein kinase R (PKR) (Chung et al, 2018), OAS1/RNase L (Li 
et al, 2017) and the RLR pathway (Liddicoat et al, 2015; Pestal et al, 2015; Mannion et al, 2014). While activation of PKR and OAS/RNase $L$ causes translational shutdown and cell death, RLR engagement initiates the type I IFN response.

The link between ADAR1 editing and RLR activation was first demonstrated in a series of mouse studies. In mice, genetic loss of ADAR1 p110 and p150, p150 alone, or knock-in of an editing-deficient ADAR1 mutant $\left(\right.$ Adar $^{\text {E861A/E861A }}$ ) results in embryonic lethality, fetal liver disintegration, hematopoiesis defects, and an elevated type I IFN signature (Wang et al, 2004; Hartner et al, 2004; Ward et al, 2011; Liddicoat et al, 2015).

The embryonic lethality of ADAR1 null or editing-deficient mice can be rescued by the concurrent deletion of the RLR family member MDA5 (melanoma differentiation-associated gene 5) or the downstream signaling hub MAVS (mitochondrial antiviral signaling, also known as VISA, Cardif, IPS-1), but not another RLR, RIG-I (retinoic-acid-inducible gene I) (Liddicoat et al, 2015; Mannion et al, 2014; Pestal et al, 2015; Heraud-Farlow \& Walkley, 2016). In addition, loss of MDA5 or MAVS also eliminates the type I IFN signature in these mice. These observations indicate that unedited RNA mediates its immunostimulatory effects via MDA5 and MAVS and that the type I IFN response plays an important role in the immunopathology caused by loss of ADAR1.

MDA5 normally detects RNA from certain viral species, such as Picornaviridae (Dias Junior et al, 2019). It senses long stretches of dsRNA or base-paired single stranded RNA, on which it oligomerizes to form filamentous structures (Dias Junior et al, 2019; Rehwinkel \& Gack, 2020). In contrast, RIG-I is activated by $5^{\prime}$ di- or triphosphate moieties at the basepaired extremities of certain viral RNA species (Goubau et al, 2013; Rehwinkel \& Gack, 2020). Activation of RIG-I or MDA5 by their respective RNA substrates leads to conformational changes that allow their $\mathrm{N}$-terminal CARD domains to interact with the 
IFN- $\beta$ ), type III IFNs and other pro-inflammatory cytokines (Goubau et al, 2013; Rehwinkel \&

STAT signaling, which results in the transcriptional upregulation of hundreds of IFNstimulated genes (ISGs), which establish an antiviral state (Schoggins et al, 2011; Schneider et al, 2014). LGP2 (laboratory of genetics and physiology 2) is the third and least wellunderstood member of the RLR family. LGP2 lacks the N-terminal CARD domains and is therefore not able to signal via MAVS (Rodriguez et al, 2014; Rehwinkel \& Gack, 2020). Instead, LGP2 modulates the function of RIG-I and MDA5 during viral infection. While LGP2 suppresses RIG-I signaling, it synergizes with MDA5 to potentiate the sensing of certain RNA viruses (Rodriguez et al, 2014; Rehwinkel \& Gack, 2020). Akin to MDA5-deficient mice, LGP2 knockout mice display increased sensitivity to infection with encephalomyocarditis virus

111 (EMCV), a member of the Picornaviridae family (Satoh et al, 2010; Venkataraman et al, 2007). Mechanistically, LGP2 is incorporated into MDA5 filaments and enhances the interaction between MDA5 and RNA, thereby increasing the rate of MDA5 filament formation (Duic et al, 2020; Bruns et al, 2014). Simultaneously, LGP2 enhances the dissociation of MDA5 filaments in an ATP-dependent manner and generates shorter

116 filaments that have greater agonistic activity than longer filaments (Duic et al, 2020; Bruns

117 et al, 2014). Structural studies demonstrated that LGP2 primarily binds the ends of dsRNA, 118 although it can also coat dsRNA in a similar fashion as MDA5 (Uchikawa et al, 2016). Thus, 
independent from its role as typical RNA sensor. Wild-type LGP2, as well as mutants that fail

processing of dsRNA (Van der Veen et al, 2018), perhaps to preserve dsRNA substrates for

regulate the antiviral type I IFN response by associating and interfering with the function of virus and lymphocytic choriomeningitis virus infection in mice, pointing to cell-type specific functions (Suthar et al, 2012). unusual Z-conformation (Z-RNA) suffer from postnatal growth retardation and mortality and have a mild type I IFN signature, which can be reverted by crossing these mice with MDA5, MAVS, PKR, as well as LGP2 knockout mice (Maurano et al, 2021). The extent to which LGP2 
from Z-RNA), the molecular mechanism that is involved, and whether it is required in

humans is unclear.

ADAR1 deficiency. Using various genetic approaches and model systems, we demonstrate

that LGP2 is essential for this induction, in a manner that involves its classical function as

RNA sensor. Importantly, we further demonstrate that LGP2 is required both for sensing of interferonopathies as well as cancer.

Results

\section{Human LGP2 is required for the induction of a type I IFN response upon depletion of}

ADAR1.

161 To investigate the role of human RLRs in the induction of type I IFN caused by absence of

162 ADAR1, we first knocked out RIG-I, MDA5, or LGP2 in the human monocytic leukemia cell

163 line THP-1 using CRISPR/Cas9-mediated genome engineering. Correct gene ablation was confirmed by immunoblotting cells treated with recombinant type I IFN to upregulate the expression of RIG-I, MDA5, and LGP2, which are encoded by ISGs themselves (Fig. 1A). Intact type I IFN receptor signaling was verified by monitoring ISG60 upregulation (Fig. 1A). For 
siRNAs targeting both isoforms of ADAR1. Despite the modest efficiency of the knockdown,

we observed a clear upregulation of transcripts encoding IFN- $\beta$ and the ISG IFIT1 in wildabrogated type I IFN induction and signaling upon ADAR1 depletion (Fig. 1B). Loss of MDA5, but not RIG-I, also interfered with the type I IFN response, consistent with published literature (Heraud-Farlow \& Walkley, 2016). Note that throughout the manuscript ADAR1 knockdown efficiency is monitored through measurement of p110 expression levels, as analysis of the p150 isoform leads to distorted results due to its IFN-inducible nature. Together these data indicate that, besides MDA5, expression of LGP2 is crucial for the induction of a type I IFN response in ADAR1 deficiency.

To further delineate the contribution of LGP2 to the sensing of unedited self RNA, we performed a similar experiment in the human cell line HEK293. Knockout of RIG-I, MDA5, or both by CRISPR/Cas9-mediated gene editing was confirmed by immunoblotting and intact type I IFN receptor signaling in the selected clones was verified by monitoring ISG60 expression upon recombinant type I IFN treatment (Fig. 1C). Unexpectedly, siRNA-mediated depletion of ADAR1 did not yield sign of a type I IFN response in parental HEK293 cells or its CRISPR/Cas9-engineered derivatives (Fig. 1D). We noted that these HEK293 cells expressed nearly undetectable levels of LGP2, even after stimulation with recombinant type I IFN

187 transduction and stable integration of a FLAG-tagged LGP2-encoding vector (Fig. 1C) enabled type I IFN induction upon siRNA-mediated ADAR1 depletion, as determined by expression of IFN- $\beta$ and IFIT1 transcripts (Fig. 1D). This was evident in MDA5-sufficient but not in MDA5-deficient cells, confirming that LGP2 and MDA5 were both necessary. As expected, loss of RIG-I did not significantly impact type I IFN induction upon ADAR1 

which suggests that MDA5 levels are not the rate-limiting factor. The ISG signature reached its maximum around 78 hours post-siRNA delivery to LGP2-overexpressing cells in cells that express both MDA5 and LGP2 (Fig. 1E). Moreover, the presence of both LGP2 and MDA5 was required for phosphorylation of IRF3 and STAT1, two key transcription factors that act downstream of MAVS and IFNAR to induce IFN- $\beta$ and ISG transcription, induction, only occurred upon expression of LGP2 in ADAR1-depleted cells (Fig. 1F). These observations demonstrate that LGP2 is essential for type I IFN induction and signaling upon ADAR1 depletion. biphasic switch that favors MDA5 signaling in response to viral ligands at low concentrations while inhibiting MDA5-dependent responses at high concentrations (Rodriguez et al, 2014). However, in our experiments, increasing amounts of an LGP2-encoding plasmid led to a gradual increase in the type I IFN response upon siRNA-mediated ADAR1 depletion without any signs of an inhibitory effect (Supplemental Fig. 1C and 1D) except at very high doses of LGP2, which negatively affect cell viability (not shown). The LGP2-dependent biphasic response previously reported in the context of viral dsRNA sensing is therefore not evident in self RNA sensing. 
where LGP2 potentiates MDA5 signaling but is not strictly required. Indeed, while bona fide

LGP2-knockout HEK293 cells failed to induce a type I IFN response upon ADAR1 depletion

218 (Supplemental Fig. 2A-B), they retained the ability to induce a (minimal) type I IFN response upon stimulation with the dsRNA mimic HMW poly(I:C) or RNA isolated from EMCV-infected cells, both of which activate MDA5 (Supplemental Fig. 2E-F). As a control, the siADAR1(Supplemental Fig. 2C-D). Whether the differential detection of self RNA versus viral RNA by LGP2/MDA5 is caused by a qualitative or quantitative difference, or both, is not clear.

Unedited self RNA may either be less abundant in cells or be a less suitable MDA5 ligand (for example because it contains only short stretches of base-paired regions as opposed to long dsRNA found in viral RNA) and therefore it may be more reliant on LGP2 for its detection. the response to unedited self RNA in ADAR1-depleted cells.

Sensing of unedited self RNA via LGP2 requires RNA binding and ATP hydrolysis.

The limited expression of LGP2 and the absence of a type I IFN response upon ADAR1 depletion in wild type HEK293 cells allowed us to create ADAR1 knockout cells through CRISPR/Cas9, without the activation of innate immune pathways that hinder cell proliferation. Two ADAR1-knockout clones were selected that completely lost expression of the ADAR1 p110 and p150 isoform yet remained responsive to type I IFNs, as determined by immunoblotting (Fig. 2A). Genetic loss of ADAR1 did not reveal a type I IFN response until introduction of LGP2 (Fig. 2B-C and Supplemental Fig. 3A-B), in line with our earlier 
largely due to the loss of the p150 isoform, as reconstitution of p150 expression completely

242 Supplemental Fig. 3A-B). In contrast, overexpression of the p110 isoform reduced, but did not block, this type I IFN response. The reduction can most likely be explained by overexpression of this isoform, which is normally restricted to the nucleus but can "spill" into the cytosol in overexpressing cells. The ADAR1-deficient cells with tunable, LGP2dependent type I IFN response, provide us therefore with a useful tool to dissect the features of LGP2 and its interaction partners that are required for unedited self RNA sensing. hydrolysis while other roles, such as interaction with MAVS and TRAFs, do not (Esser-Nobis et al, 2020; Parisien et al, 2018). We introduced, by means of lentiviral transduction, a doxycycline-inducible system to stably express FLAG-LGP2 WT or a mutant that completely fails to bind RNA (FLAG-LGP2 K138E/R490E/K634E, denoted as "LGP2 KRK" in figures) in ADAR1 KO cells (Fig. 3A-B). Doxycycline-induced expression of LGP2 WT in ADAR1 KO cells led to robust ISG60 protein (Fig. 3A) and IFN- $\beta$ and IFIT1 transcript induction (Fig. 3B). In contrast, expression of the LGP2 RNA-binding mutant did not induce a type I IFN response.

257 Consistent with these findings, induction of LGP2 WT, but not the RNA-binding mutant, allowed nuclear translocation of IRF3 (Fig. 3C). These observations indicate that binding to RNA substrates is required for LGP2-dependent type I IFN induction in ADAR1-deficient cells. To determine whether LGP2 is required for MDA5 oligomerization in ADAR1-

261 deficient cells, we utilized semi-denaturing detergent agarose gel electrophoresis (SDD-AGE) to monitor MDA5 aggregation. To circumvent discrepancies in MDA5 protein levels across samples (due to its increased expression as an ISG in LGP2-expressing ADAR1 KO cells), we 
treated cells with recombinant type I IFN to equalize MDA5 expression (Fig. 3D, SDS-PAGE).

Doxycycline-inducible expression of LGP2 WT, but not the RNA-binding mutant, revealed MDA5 oligomerization and activation in the ADAR1-induced type I IFN response.

4A) in ADAR1 knockout cells and observed that, besides RNA binding, full length LGP2 and of the LGP2 N-terminal domain (NTD), C-terminal domain (CTD), or mutation of LGP2 residues that are critical for ATPase activity (K30A) or RNA binding via the LGP2 NTD (K138E/R490E) or CTD (K634E) (Pippig et al, 2009; Uchikawa et al, 2016; Bruns et al, 2013), all abolished IFN induction in ADAR1-deficient cells (Fig. 4B-C). to the dsRNA-binding protein PACT (C615A) (Sanchez David et al, 2019) also prevented type unedited self RNA (Fig. 4B-C). Of note, C615 is also important for the correct orientation of a $\mathrm{Zn}^{2+}$ ion in LGP2 (Pippig et al, 2009), hence the role of PACT and/or $\mathrm{Zn}^{2+}$ binding will need to be evaluated in further studies. 
type I IFN response in ADAR1 knockout cells, while the Q390R/T395R mutation reduced, but role in type I IFN induction upon picornavirus infection or perhaps regulates alternative, non-canonical functions of LGP2, needs to be further explored in a TRIM14-deficient setting. We conclude that, besides RNA binding, ATP hydrolysis is strictly required for LGP2 to mediate type I IFN induction in ADAR1-deficient cells. This suggests that the function of LGP2 in inflammation in ADAR1 deficiency involves its canonical role as RNA sensor rather than an 'indirect' role, e.g., via its interaction with MAVS or TRAFs. In addition, the binding of LGP2 to PACT or a $\mathrm{Zn}^{2+}$ ion is important for type I IFN induction in ADAR1-deficient cells.

\section{LGP2 is required for growth retardation of tumor cells and cell-intrinsic inflammation}

\section{upon loss of ADAR1, which is potentiated by epigenetic therapy}

Recent studies have placed ADAR1 in the spotlight as an attractive novel drug target to enhance anti-tumor immunity (Bhate et al, 2019). To explore the relationship between LGP2 analysis of ADAR1 and LGP2 (encoded by ADAR and DHX58, respectively) mRNA expression in multiple cancer types using data from The Cancer Genome Atlas (TCGA). We hypothesized that patients with high $D H X 58$ expression $\left(D H X 58^{\text {high }}\right)$ would have improved survival compared to patients with low $D H X 58$ expression $\left(D H X 58^{\text {low }}\right)$ in patients with low $A D A R$ expression $\left(A D A R^{\text {low }}\right)$. Patients were stratified into four groups according to $A D A R$ and 
patients (Fig. 5A and Supplemental Fig. 4). In contrast, no difference in survival was found in $A D A R^{\text {high }}$ cancer patients stratified based on $D H X 58$ levels. This observation was most striking in bladder cancer (BLCA), sarcoma (SARC) and breast cancer (BRCA) (Fig. 5A). Thus, LGP2 mRNA abundance is linked to improved outcomes specifically in patients with low levels of ADAR1 across multiple malignancies. and LGP2 in tumors, or are merely a consequence of increased ISG expression in tumors with low ADAR1 expression, cannot be determined through bioinformatic analysis. To explore this experimentally, we used doxycycline-inducible shRNA-mediated knockdown of ADAR1 in a human oral squamous cell carcinoma cell line (CAL27), which was previously shown to be sensitive to ADAR1 loss (Liu et al, 2019) and that upregulates LGP2 upon type I IFN treatment (Supplemental Fig. 5A). As predicted, knockdown of ADAR1 inhibited cell proliferation of CAL27 cells, whereas this was not the case upon expression of a control shRNA targeting GFP (Fig. 5B). Importantly, simultaneous knockdown of LGP2 using two independent siRNAs resulted in a partial rescue of cell growth after ADAR1 knockdown (Fig. 5B). ADAR1 and LGP2 knockdown efficiencies were validated by RT-qPCR (Supplemental Fig. incomplete knockdown of LGP2 as well as the activation of PKR upon ADAR1 loss, as reported (Chung et al, 2018; Liu et al, 2019). We conclude that loss of LGP2 in part suppresses ADAR1 shRNA-induced growth retardation. 
bioRxiv preprint doi: https://doi.org/10.1101/2021.10.27.465188; this version posted October 28,2021 . The copyright holder for this preprint (which was not certified by peer review) is the author/funder, who has granted bioRxiv a license to display the preprint in perpetuity. It is made available under aCC-BY-NC-ND 4.0 International license.

together with shRNA-mediated depletion of ADAR1 induces an MDA5-dependent type I IFN response through the increased expression of IR-Alu elements that are no longer edited

338 (Mehdipour et al, 2020). To test whether this involves LGP2, we used siRNAs to deplete ADAR1, either alone or in combination with an siRNA targeting LGP2, in human colorectal adenocarcinoma cells (HT29). As expected, loss of ADAR1 triggered a strong type I IFN response in these cells, as determined by expression of IFN- $\beta$ and two ISGs (IFIT1 and ISG15), but this was completely blocked upon simultaneous depletion of LGP2

343 (Supplemental Fig. 5C). The siADAR1-mediated IFN response was further enhanced upon 5-

344 AZA-CdR treatment of HT29 cells (Fig. 6A), as previously reported (Mehdipour et al, 2020).

345 Notably, the synergistic effect between ADAR1 depletion and 5-AZA-CdR treatment was also

346 strictly dependent on LGP2 (Fig. 6A). In contrast, the elevated type I IFN response induced

347 by treatment with 5-AZA-CdR alone was less dependent on LGP2, which indicates that some

348 stimulatory RNAs that are demethylated and expressed upon 5-AZA-CdR treatment per se

349 partially escape recognition by LGP2, likely through ADAR1-mediated RNA editing.

350 Knockdown efficiencies of ADAR1 and LGP2 were determined by RT-qPCR analysis

351 (Supplemental Fig. 5C). The above observations were confirmed in another human colorectal carcinoma cell line (LIM1215) (Fig. 6B and Supplemental Fig. 5D). To further explore the LGP2-dependent synergy between ADAR1 depletion and anti-cancer therapies, we treated cells with ADAR1-targeting siRNAs in the presence or absence of the CDK4/6

355 inhibitor palbociclib, which also upregulates levels of endogenous stimulatory RNAs (Goel et al, 2017). Combined treatment with ADAR1 siRNAs and palbociclib caused a synergistic

357 upregulation of IFN- $\beta$ and ISGs, as described (Mehdipour et al, 2020), which was also strictly 
bioRxiv preprint doi: https://doi.org/10.1101/2021.10.27.465188; this version posted October 28,2021 . The copyright holder for this preprint (which was not certified by peer review) is the author/funder, who has granted bioRxiv a license to display the preprint in perpetuity. It is made available under aCC-BY-NC-ND 4.0 International license.

inflammatory response upon combined epigenetic therapy and ADAR1 depletion in tumor cells.

\section{Discussion}

Nucleic acid sensors continuously survey their environment for the presence of nucleic acid structures that are commonly found on viral RNA. Various cellular mechanisms allow the discrimination between viral (non-self) nucleic acids and cellular (self) DNA or RNA. These mechanisms, however, are not foolproof. Loss of ADAR1-dependent RNA editing causes unwanted recognition of self RNA and consequently inadvertent innate immune activation and severe pathology (Rodero \& Crow, 2016; Rice et al, 2012, 2017; Livingston \& Crow, 2016). Various nucleic acid sensors, including PKR, OAS/RNase $L$ and MDA5, sense unedited self RNA and cause translational shutdown, cell death and autoinflammation, marked by the production of type I IFNs (Quin et al, 2021). Here we demonstrate that the RNA helicase LGP2 is indispensable for type I IFN induction in ADAR1-deficient human cells. We further demonstrate that this involves the canonical role of LGP2 as a sensor of base-paired RNA, which requires ATP hydrolysis and intact RNA binding sites and enables MDA5 oligomerization. We extend our findings to multiple cancer cell lines (THP-1, CAL27, HT29 and LIM1215) and demonstrate that the sensitivity of tumor cells to ADAR1 loss requires the presence of LGP2. Moreover, the previously reported synergistic effects of ADAR1 depletion and epigenetic therapy on the intrinsic type I IFN response in cancer cells are also strictly dependent on LGP2. These findings have several important implications, which are discussed below. 
when found in close proximity to each other and in inverted orientation, increases the risk degree of complementarity in such RNAs and minimize accidental innate immune activation. stem regions of Alu and IR-Alu elements while being more frequent within predicted single stranded regions (Chung et al, 2018). In addition, endogenous base-paired RNAs with nearperfect complementarity are scarce amongst mRNAs (but not pre-mRNAs) (Barak et al, 2020). In mice, transcriptomic analysis of ADAR p110/ADAR2-deficient brain tissue revealed as few as 36 ADAR1 p150-specific editing sites (Kim et al, 2021). Thus, potentially, only few RNAs become truly stimulatory when no longer edited in intact cells or tissues. The 
406

407

408

409

410

411

412

413

414

415

416

417

418

419

420

421

422

423

424

425

426

427

428

429

(Z $\alpha$ ) binding domain (de Reuver et al, 2021; Tang et al, 2021; Nakahama et al, 2021;

Maurano et al, 2021; Zillinger \& Bartok, 2021). In mice, various mutations in the Z $\alpha$ domain of ADAR1 result in postnatal growth retardation and mortality as well as an increased type I

IFN signature (de Reuver et al, 2021; Maurano et al, 2021; Nakahama et al, 2021; Tang et al, 2021). Transcripts that are prone to adopt a Z-conformation, such as those with purinepyrimidine repeats (Koeris et al, 2005), can therefore be immunostimulatory and this can be reduced by A-to-I editing. The precise identity and features of immunogenic RNAs remains unresolved. Protein-RNA interaction studies, such as individual-nucleotide resolution UVcrosslinking and immunoprecipitation (iCLIP), may help to identify RNAs that directly engage dsRNA sensors. The role of LGP2 in unedited self RNA sensing opens up the possibility to retrieve immunogenic RNAs via their association with LGP2 in ADAR1-deficient cells, as has been done in the context of viral infection (Deddouche et al, 2014). Our observation that type I IFN induction upon loss of ADAR1 is strictly dependent on LGP2, which favors the formation of short RNA filaments (Bruns et al, 2014), hints at the possibility that the stimulatory RNA in ADAR1 deficiency is shorter than 'classical' MDA5 substrates, which tend to be long complex dsRNAs of > 1000/2000 nt in length (Pichlmair et al, 2009; Kato et al, 2021).

Besides ADAR1, eight disease-causative mutations have been identified in AGS, including gain-of-function mutations in IFIH1 (encoding MDA5), all of which cause an elevated type I IFN signature (Livingston \& Crow, 2016; Rodero \& Crow, 2016; Uggenti et al, $2019,2020)$. Currently there is no licensed therapy for treatment of AGS or related interferonopathies (Crow et al, 2020). A few individual reports describe encouraging clinical improvements upon treatment of a small number of patients with the JAK1/2 inhibitor ruxolitinib, which blocks signaling downstream of the IFNAR (Crow et al, 2020). However, 
JAK1/2 inhibition is rather non-specific and will block pathways beyond type I IFN signaling.

In addition, transcriptional activity of IRF3 and NF-אB leads to upregulation of other genes

441 (mimicking the most common ADAR mutation in AGS at P193), were intercrossed with

442 various knockout models, including Dhx58\%- mice (Maurano et al, 2021). LGP2 deficiency

443 rescued the postnatal mortality of $A_{d a r^{P 195 A / P 150-}}$ mice and abolished the type I IFN signature.

444 Thus, LGP2 is an essential effector molecule of ADAR1-driven disease in both mice and humans. Loss of PKR also rescued the mortality of $A D A R^{P 195 A / p 150-}$ mice, yet the type I IFN signature remained elevated (Maurano et al, 2021), consistent with previous literature 447 showing that activation of PKR is largely responsible for ADAR1-associated translational shutdown, cell death and pathology but not IFN-driven inflammation (Chung et al, 2018). In contrast to its disease-causing role in AGS, ADAR1 is an exciting new immunooncology target and several in vitro and in vivo studies have highlighted that its deletion

451 increases tumor cell lethality and renders tumors more vulnerable to immunotherapy

452 (Gannon et al, 2018; Liu et al, 2019; Ishizuka et al, 2019). We observed that depletion of

453 ADAR1 in multiple tumor cell lines triggered a type I IFN response in an LGP2-dependent 
manner. Moreover, the reported synergy between ADAR1 deletion and epigenetic therapy delayed cell growth upon ADAR1 knockdown. Altogether this demonstrates that LGP2 is a hitherto overlooked, yet essential, player when targeting ADAR1. It also predicts that LGP2sufficient tumors are more likely to respond to ADAR1-directed therapies than LGP2deficient tumors. Indeed, across multiple human tumor types, patient stratification based on ADAR1 and LGP2 transcript levels revealed that patients with high LGP2 and concomitant low ADAR1 levels had improved survival. The relationship between ADAR1 and LGP2 and its impact on tumor growth, the intra-tumoral inflammatory response, and anti-tumor immunity will need to be further evaluated in in vivo models. for potential ADAR1-directed cancer therapy.

\section{Acknowledgements}

We are grateful to Dr. Maaike Ressing and Dr. Jan Rehwinkel for critical reading of this manuscript. We thank Dr. Jannie Borst and all members of our laboratory for helpful discussions and suggestions. This work was supported by a fellowship from the Leiden

University Medical Centre and a research grant from the Institute for Chemical Immunology

474 (ICl-00203), which is funded by a Gravitation project from the Netherlands Organization for

475 Scientific Research (NWO). CPB and SZ are supported by the NIHR Manchester Biomedical

476 Research Centre and by a Cancer Research UK Manchester Institute Award (A19258). CRS is 
UK (FC001136), the UK Medical Research Council (FC001136), and the Wellcome Trust

\section{Author Contributions}

JES, TO, and AGV designed experiments and analyzed data. JES, TO, and AGV conducted authors reviewed the manuscript.

491

\section{Conflict of Interest}

CRS has an additional appointment as Professor in the Faculty of Medicine at Imperial 
501

502

503

504

505

506

507

508

509

510

511

512

513

514

515

516

517

518

519

520

521

522

523

524

525

526

527

528

529

530

531

532

533

534

535

536

537

538

539

540

541

542

543

544

545

546

547

\section{References}

Ablasser A \& Hur S (2020) Regulation of cGAS- and RLR-mediated immunity to nucleic acids. Nat Immunol 21: 17-29

Ahmad S, Mu X, Yang F, Greenwald E, Park JW, Jacob E, Zhang C-Z \& Hur S (2018) Breaching Self-Tolerance to Alu Duplex RNA Underlies MDA5-Mediated Inflammation. Cell 172: 797-810.e13

Andersen J, VanScoy S, Cheng T-F, Gomez D \& Reich NC (2008) IRF-3-dependent and augmented target genes during viral infection. Genes Immun 9: 168-175

Barak M, Porath HT, Finkelstein G, Knisbacher BA, Buchumenski I, Roth SH, Levanon EY \& Eisenberg E (2020) Purifying selection of long dsRNA is the first line of defense against false activation of innate immunity. Genome Biol 21: 26

Bhate A, Sun T \& Li JB (2019) ADAR1: A New Target for Immuno-oncology Therapy. Mol Cell 73: 866-868

Bruns AM, Leser GP, Lamb RA \& Horvath CM (2014) The Innate Immune Sensor LGP2 Activates Antiviral Signaling by Regulating MDA5-RNA Interaction and Filament Assembly. Mol Cell 55: 771-781

Bruns AM, Pollpeter D, Hadizadeh N, Myong S, Marko JF \& Horvath CM (2013) ATP Hydrolysis Enhances RNA Recognition and Antiviral Signal Transduction by the Innate Immune Sensor, Laboratory of Genetics and Physiology 2 (LGP2). J Biol Chem 288: 938946

Chen X, Rinsma M, Janssen JM, Liu J, Maggio I \& Gonçalves MAFV (2016) Probing the impact of chromatin conformation on genome editing tools. Nucleic Acids Res 44: 6482-6492

Chiappinelli KB, Strissel PL, Desrichard A, Li H, Henke C, Akman B, Hein A, Rote NS, Cope LM, Snyder A, et al (2015) Inhibiting DNA Methylation Causes an Interferon Response in Cancer via dsRNA Including Endogenous Retroviruses. Cell 162: 974-986

Chung H, Calis JJA, Wu X, Sun T, Yu Y, Sarbanes SL, Dao Thi VL, Shilvock AR, Hoffmann H-H, Rosenberg BR, et al (2018) Human ADAR1 Prevents Endogenous RNA from Triggering Translational Shutdown. Cell 172: 811-824.e14

Crow YJ, Shetty J \& Livingston JH (2020) Treatments in Aicardi-Goutières syndrome. Dev Med Child Neurol 62: 42-47

Deddouche S, Goubau D, Rehwinkel J, Chakravarty P, Begum S, Maillard P V., Borg A, Matthews N, Feng Q, van Kuppeveld FJM, et al (2014) Identification of an LGP2associated MDA5 agonist in picornavirus-infected cells. eLife 3: 1-20

Deininger P (2011) Alu elements: Know the SINEs. Genome Biol 12: 1-12

Dias Junior AG, Sampaio NG \& Rehwinkel J (2019) A Balancing Act: MDA5 in Antiviral Immunity and Autoinflammation. Trends Microbiol 27: 75-85

Duic I, Tadakuma H, Harada Y, Yamaue R, Deguchi K, Suzuki Y, Yoshimura SH, Kato H, Takeyasu K \& Fujita T (2020) Viral RNA recognition by LGP2 and MDA5, and activation of signaling through step-by-step conformational changes. Nucleic Acids Res 48: 1166411674

Eisenberg E \& Levanon EY (2018) A-to-I RNA editing - immune protector and transcriptome diversifier. Nat Rev Genet 19: 473-490

Esser-Nobis K, Hatfield LD \& Gale M (2020) Spatiotemporal dynamics of innate immune signaling via RIG-I-like receptors. Proc Natl Acad Sci 117: 15778-15788

Gannon HS, Zou T, Kiessling MK, Gao GF, Cai D, Choi PS, Ivan AP, Buchumenski I, Berger AC, 
Goldstein JT, et al (2018) Identification of ADAR1 adenosine deaminase dependency in a subset of cancer cells. Nat Commun 9: 5450

Goel S, DeCristo MJ, Watt AC, BrinJones H, Sceneay J, Li BB, Khan N, Ubellacker JM, Xie S, Metzger-Filho O, et al (2017) CDK4/6 inhibition triggers anti-tumour immunity. Nature 548: 471-475

Goubau D, Deddouche S \& Reis e Sousa C (2013) Cytosolic Sensing of Viruses. Immunity 38: 855-869

Hartner JC, Schmittwolf C, Kispert A, Müller AM, Higuchi M \& Seeburg PH (2004) Liver Disintegration in the Mouse Embryo Caused by Deficiency in the RNA-editing Enzyme ADAR1. J Biol Chem 279: 4894-4902

Heraud-Farlow JE \& Walkley CR (2016) The role of RNA editing by ADAR1 in prevention of innate immune sensing of self-RNA. J Mol Med 94: 1095-1102

Ishizuka JJ, Manguso RT, Cheruiyot CK, Bi K, Panda A, Iracheta-Vellve A, Miller BC, Du PP, Yates KB, Dubrot J, et al (2019) Loss of ADAR1 in tumours overcomes resistance to immune checkpoint blockade. Nature 565: 43-48

Jiang W, Hua R, Wei M, Li C, Qiu Z, Yang X \& Zhang C (2015) An optimized method for hightiter lentivirus preparations without ultracentrifugation. Sci Rep 5: 1-9

Kato K, Ahmad S, Zhu Z, Young JM, Mu X, Park S, Malik HS \& Hur S (2021) Structural analysis of RIG-I-like receptors reveals ancient rules of engagement between diverse RNA helicases and TRIM ubiquitin ligases. Mol Cell 81: 599-613.e8

Kim JI, Nakahama T, Yamasaki R, Costa Cruz PH, Vongpipatana T, Inoue M, Kanou N, Xing Y, Todo $\mathrm{H}$, Shibuya T, et al (2021) RNA editing at a limited number of sites is sufficient to prevent MDA5 activation in the mouse brain. PLOS Genet 17: e1009516

Koeris M, Funke L, Shrestha J, Rich A \& Maas S (2005) Modulation of ADAR1 editing activity by Z-RNA in vitro. Nucleic Acids Res 33: 5362-5370

Li Y, Banerjee S, Goldstein SA, Dong B, Gaughan C, Rath S, Donovan J, Korennykh A, Silverman RH \& Weiss SR (2017) Ribonuclease $L$ mediates the cell-lethal phenotype of double-stranded RNA editing enzyme ADAR1 deficiency in a human cell line. elife 6

Liddicoat BJ, Piskol R, Chalk AM, Ramaswami G, Higuchi M, Hartner JC, Li JB, Seeburg PH \& Walkley CR (2015) RNA editing by ADAR1 prevents MDA5 sensing of endogenous dsRNA as nonself. Science 349: 1115-1120

Liu H, Golji J, Brodeur LK, Chung FS, Chen JT, DeBeaumont RS, Bullock CP, Jones MD, Kerr G, Li L, et al (2019) Tumor-derived IFN triggers chronic pathway agonism and sensitivity to ADAR loss. Nat Med 25: 95-102

Livingston J \& Crow Y (2016) Neurologic Phenotypes Associated with Mutations in TREX1, RNASEH2A, RNASEH2B, RNASEH2C, SAMHD1, ADAR1, and IFIH1: Aicardi-Goutières Syndrome and Beyond. Neuropediatrics 47: 355-360

Maggio I, Holkers M, Liu J, Janssen JM, Chen X \& Gonçalves MAFV (2014) Adenoviral vector delivery of RNA-guided CRISPR/Cas9 nuclease complexes induces targeted mutagenesis in a diverse array of human cells. Sci Rep 4: 1-11

Mannion NM, Greenwood SM, Young R, Cox S, Brindle J, Read D, Nellåker C, Vesely C, Ponting CP, McLaughlin PJ, et al (2014) The RNA-Editing Enzyme ADAR1 Controls Innate Immune Responses to RNA. Cell Rep 9: 1482-1494

Maurano M, Snyder JM, Connelly C, Henao-Mejia J, Sidrauski C \& Stetson DB (2021) Protein kinase $R$ and the integrated stress response drive immunopathology caused by mutations in the RNA deaminase ADAR1. Immunity 54: 1948-1960.e5

Mehdipour P, Marhon SA, Ettayebi I, Chakravarthy A, Hosseini A, Wang Y, de Castro FA, Loo 
Yau H, Ishak C, Abelson S, et al (2020) Epigenetic therapy induces transcription of inverted SINEs and ADAR1 dependency. Nature 588: 169-173

Nakahama T, Kato Y, Shibuya T, Inoue M, Kim JI \& Vongpipatana T (2021) Article Mutations in the adenosine deaminase ADAR1 that prevent endogenous Z-RNA binding induce Aicardi- Goutie II Article Mutations in the adenosine deaminase ADAR1 that prevent endogenous Z-RNA binding induce ' res-syndrome-like encephalopathy Aicardi-G. Immunity 54: 1976-1988.e7

Parisien J, Lenoir JJ, Mandhana R, Rodriguez KR, Qian K, Bruns AM \& Horvath CM (2018) RNA sensor LGP2 inhibits TRAF ubiquitin ligase to negatively regulate innate immune signaling. EMBO Rep 19: 1-14

Pestal K, Funk CC, Snyder JM, Price ND, Treuting PM \& Stetson DB (2015) Isoforms of RNAEditing Enzyme ADAR1 Independently Control Nucleic Acid Sensor MDA5-Driven Autoimmunity and Multi-organ Development. Immunity 43: 933-944

Pichlmair A, Schulz O, Tan C-P, Rehwinkel J, Kato H, Takeuchi O, Akira S, Way M, Schiavo G \& Reis e Sousa C (2009) Activation of MDA5 Requires Higher-Order RNA Structures Generated during Virus Infection. J Virol 83: 10761-10769

Pippig DA, Hellmuth JC, Cui S, Kirchhofer A, Lammens K, Lammens A, Schmidt A, Rothenfusser S \& Hopfner K-P (2009) The regulatory domain of the RIG-I family ATPase LGP2 senses double-stranded RNA. Nucleic Acids Res 37: 2014-2025

Quin J, Sedmík J, Vukić D, Khan A, Keegan LP \& O'Connell MA (2021) ADAR RNA Modifications, the Epitranscriptome and Innate Immunity. Trends Biochem Sci 46: 758771

Ramaswami G \& Li JB (2016) Identification of human RNA editing sites: A historical perspective. Methods 107: 42-47

Ramaswami G, Lin W, Piskol R, Tan MH, Davis C \& Li JB (2012) Accurate identification of human Alu and non-Alu RNA editing sites. Nat Methods 9: 579-581

Rehwinkel J \& Gack MU (2020) RIG-l-like receptors: their regulation and roles in RNA sensing. Nat Rev Immunol 20: 537-551

de Reuver R, Dierick E, Wiernicki B, Staes K, Seys L, De Meester E, Muyldermans T, Botzki A, Lambrecht BN, Van Nieuwerburgh F, et al (2021) ADAR1 interaction with Z-RNA promotes editing of endogenous double-stranded RNA and prevents MDA5-dependent immune activation. Cell Rep 36: 109500

Rice G, Kitabayashi N, Barth M, Briggs T, Burton A, Carpanelli M, Cerisola A, Colson C, Dale R, Danti F, et al (2017) Genetic, Phenotypic, and Interferon Biomarker Status in ADAR1Related Neurological Disease. Neuropediatrics 48: 166-184

Rice GI, Kasher PR, Forte GMA, Mannion NM, Greenwood SM, Szynkiewicz M, Dickerson JE, Bhaskar SS, Zampini M, Briggs TA, et al (2012) Mutations in ADAR1 cause AicardiGoutières syndrome associated with a type I interferon signature. Nat Genet 44: 12431248

Rodero MP \& Crow YJ (2016) Type I interferon-mediated monogenic autoinflammation: The type I interferonopathies, a conceptual overview. J Exp Med 213: 2527-2538

Rodriguez KR, Bruns AM \& Horvath CM (2014) MDA5 and LGP2: Accomplices and Antagonists of Antiviral Signal Transduction. J Virol 88: 8194-8200

Roulois D, Loo Yau H, Singhania R, Wang Y, Danesh A, Shen SY, Han H, Liang G, Jones PA, Pugh TJ, et al (2015) DNA-Demethylating Agents Target Colorectal Cancer Cells by Inducing Viral Mimicry by Endogenous Transcripts. Cell 162: 961-973

Sanchez David RY, Combredet C, Najburg V, Millot GA, Beauclair G, Schwikowski B, Léger T, 
Camadro JM, Jacob Y, Bellalou J, et al (2019) LGP2 binds to PACT to regulate RIG-I- and MDA5-mediated antiviral responses. Sci Signal 12: eaar3993

Satoh T, Kato H, Kumagai Y, Yoneyama M, Sato S, Matsushita K, Tsujimura T, Fujita T, Akira S \& Takeuchi O (2010) LGP2 is a positive regulator of RIG-I- and MDA5-mediated antiviral responses. Proc Natl Acad Sci 107: 1512-1517

Schlee M \& Hartmann G (2016) Discriminating self from non-self in nucleic acid sensing. Nat Rev Immunol 16: 566-580

Schneider WM, Chevillotte MD \& Rice CM (2014) Interferon-Stimulated Genes: A Complex Web of Host Defenses. Annu Rev Immunol 32: 513-545

Schoggins JW, Wilson SJ, Panis M, Murphy MY, Jones CT, Bieniasz P \& Rice CM (2011) A diverse range of gene products are effectors of the type I interferon antiviral response. Nature 472: 481-485

Sohn J \& Hur S (2016) Filament assemblies in foreign nucleic acid sensors. Curr Opin Struct Biol 37: 134-144

Stok JE, Vega Quiroz ME \& van der Veen AG (2020) Self RNA Sensing by RIG-I-like Receptors in Viral Infection and Sterile Inflammation. J Immunol 205: 883-891

Streicher F \& Jouvenet N (2019) Stimulation of Innate Immunity by Host and Viral RNAs. Trends Immunol 40: 1134-1148

Suthar MS, Ramos HJ, Brassil MM, Netland J, Chappell CP, Blahnik G, McMillan A, Diamond MS, Clark EA, Bevan MJ, et al (2012) The RIG-I-like Receptor LGP2 Controls CD8 ${ }^{+}$T Cell Survival and Fitness. Immunity 37: 235-248

Tang Q, Rigby RE, Young GR, Townsend AR, Kassiotis G, Tang Q, Rigby RE, Young GR, Hvidt AK, Davis T, et al (2021) Article Adenosine-to-inosine editing of endogenous Z-form RNA by the deaminase ADAR1 prevents spontaneous MAVS-dependent type I interferon responses II Adenosine-to-inosine editing of endogenous Z-form RNA by the deaminase ADAR1 prevents spontaneous MAVS-. Immunity 54: 1961-1975.e5

Uchikawa E, Lethier M, Malet H, Brunel J, Gerlier D \& Cusack S (2016) Structural Analysis of dsRNA Binding to Anti-viral Pattern Recognition Receptors LGP2 and MDA5. Mol Cell 62: 586-602

Uggenti C, Lepelley A \& Crow YJ (2019) Self-Awareness: Nucleic Acid-Driven Inflammation and the Type I Interferonopathies. Annu Rev Immunol 37: 247-267

Uggenti C, Lepelley A, Depp M, Badrock AP, Rodero MP, El-Daher MT, Rice GI, Dhir S, Wheeler AP, Dhir A, et al (2020) cGAS-mediated induction of type I interferon due to inborn errors of histone pre-mRNA processing. Nat Genet 52: 1364-1372

van der Veen AG, Maillard P V, Schmidt JM, Lee SA, Deddouche-Grass S, Borg A, Kjær S, Snijders AP \& Reis e Sousa C (2018) The RIG-I-like receptor LGP2 inhibits Dicerdependent processing of long double-stranded RNA and blocks RNA interference in mammalian cells. EMBO J 37: e97479

Venkataraman T, Valdes M, Elsby R, Kakuta S, Caceres G, Saijo S, Iwakura Y \& Barber GN (2007) Loss of DExD/H Box RNA Helicase LGP2 Manifests Disparate Antiviral Responses. J Immunol 178: 6444-6455

Wang Q, Miyakoda M, Yang W, Khillan J, Stachura DL, Weiss MJ \& Nishikura K (2004) Stressinduced Apoptosis Associated with Null Mutation of ADAR1 RNA Editing Deaminase Gene. J Biol Chem 279: 4952-4961

Ward S V., George CX, Welch MJ, Liou L-Y, Hahm B, Lewicki H, de la Torre JC, Samuel CE \& Oldstone MB (2011) RNA editing enzyme adenosine deaminase is a restriction factor for controlling measles virus replication that also is required for embryogenesis. Proc 
bioRxiv preprint doi: https://doi.org/10.1101/2021.10.27.465188; this version posted October 28, 2021. The copyright holder for this

preprint (which was not certified by peer review) is the author/funder, who has granted bioRxiv a license to display the preprint in perpetuity. It is made available under aCC-BY-NC-ND 4.0 International license.

689

Natl Acad Sci 108: 331-336

690 Zillinger T \& Bartok E (2021) ADAR1 edits the SenZ and SenZ-ability of RNA. Immunity 54:

691 1909-1911

692

693

694 
Figure 1: Human LGP2 is essential for the induction of a type I IFN response upon

depletion of ADAR1. A) THP-1 monocytes were genetically engineered to knockout RIG-I,

MDA5, or LGP2 using CRISPR/Cas9. Cells were differentiated towards macrophage-like cells generated in $(A)$ were differentiated using PMA and transfected with a control siRNA (siCtrl) or an ADAR1-targeting siRNA (siADAR1). The type I IFN response was monitored 56h posttransfection by RT-qPCR analysis to determine IFN- $\beta$ and IFIT1 transcript expression, normalized to a housekeeping gene (ACTB). ADAR1 knockdown efficiency was monitored by ADAR1 p110 expression, normalized to ACTB and displayed relative to siCtrl. Data from a representative experiment are shown with mean \pm s.d. $(n=3)$. C) HEK293 cells were genetically engineered to knockout RIG-I, MDA5, or both, and subsequently subjected to retroviral transduction to stably express FLAG-LGP2 or an empty vector (EV). Correct gene editing and intact type I IFN responsiveness was validated by SDS-PAGE and immunoblotting using the indicated antibodies $(n=2) .{ }^{*}$, non-specific band.

D) Cells generated in (C) were transfected with siCtrl or siADAR1. The type I IFN response and ADAR1 knockdown efficiency was monitored 78h post-transfection as in (B). Data from a representative experiment are shown with mean \pm s.d. $(n=4)$. E) Cells generated in $(C)$ were transfected with siCtrl $(s i C)$ or siADAR1 (siA). Protein lysates were prepared 78h post-transfection, followed by SDS-PAGE and immunoblotting using the indicated antibodies $(n=2)$. F) HEK293 cells and FLAG-LGP2- 
coverslips for immunofluorescence. Cells were fixed, permeabilized and stained $72 \mathrm{~h}$ post-

Figure 2: A type I IFN response is unleashed in ADAR1 knockout cells upon expression of

LGP2. A) HEK293 cells were genetically engineered to knockout ADAR1 using CRISPR/Cas9. were analyzed by SDS-PAGE followed by immunoblotting using the indicated antibodies

(EV) or a FLAG-LGP2-encoding vector (LGP2) combined with a vector encoding GFP-tagged response was monitored by RT-qPCR analysis of IFN- $\beta$ and IFIT1 expression, normalized to

Figure 3: RNA binding by LGP2 is required for receptor oligomerization and type I IFN

740 induction in ADAR1 knockout cells. A) ADAR1-knockout HEK293 cells (clone 1) were 
743

regulated manner. Cells were treated $72 \mathrm{~h}$ with doxycycline (dox). Protein lysates were analyzed by SDS-PAGE and immunoblotting using the indicated antibodies $(n=3)$. iEV $=$ inducible empty vector; iLGP2 = inducible LGP2. B) Cells generated in (A) were treated with doxycycline for $72 \mathrm{~h}$ to induce LGP2 WT or KRK mutant gene expression. The type I IFN response was monitored by RT-qPCR analysis of IFN- $\beta$ and IFIT1 transcript expression, normalized to ACTB. Gene induction was monitored by DHX58 (encoding LGP2) transcript expression, normalized to ACTB. Data from a representative experiment are shown with mean \pm s.d. $(n=3)$. C) Cells generated in $(A)$ were plated on coverslips and treated with or without doxycycline for $72 \mathrm{~h}$. Cells were fixed, permeabilized and stained with anti-FLAG and anti-IRF3 antibodies. Total nuclei ( $>500$ nuclei per experimental condition) and IRF3-positive nuclei were counted using semi-automated software analysis and plotted as percentage IRF3-positive nuclei of total nuclei ( $n=2 ; 1$ representative quantified). Statistical analysis was performed using one-way ANOVA with Sidak's correction for multiple comparisons. ns, not significant; ${ }^{* * *}, \mathrm{p}<0.0001$. D) Cells generated in $(A)$ were treated with doxycycline for $72 \mathrm{~h}$. During the last $24 \mathrm{~h}$, recombinant type I IFN was added to upregulate endogenous MDA5 protein expression. Protein lysates were analyzed by SDD-AGE and SDS-PAGE using the indicated antibodies to determine protein oligomerization and total expression levels, respectively $(n=3)$.

Figure 4: The function of LGP2 in sensing unedited self RNA involves its canonical role as dsRNA sensor that requires RNA binding and ATP hydrolysis. A) Schematic illustration of the domain structure of LGP2 and various point mutants and truncation mutants that are used in this study. The N-terminal domain (NTD) of LGP2 is composed of a conserved DExH/D helicase domain, subdivided into the helicase 1 (Hel1), helicase 2 (Hel2) and 
helicase insertion (Hel2i) domain, and a pincer motif (P). The NTD is followed by a C-terminal domain (CTD), involved in RNA binding. B) HEK293 WT or ADAR1-knockout cells (clone 1) were transiently transfected with vectors encoding the indicated truncation or point mutants and harvested $72 \mathrm{~h}$ post-transfection. The type I IFN response was monitored by RTqPCR analysis of IFN- $\beta$ and IFIT1 transcript expression, normalized to ACTB. Data from a representative experiment are shown with mean \pm s.d. $(n=3)$. C) Cells were treated as in (B). Protein lysates were prepared and analyzed by SDS-PAGE followed by immunoblotting using the indicated antibodies $(n=3)$.

Figure 5: Reduced tumor cell growth upon loss of ADAR1 is dependent on LGP2. A) Kaplan-

Meier plots showing overall survival of $A D A R^{\text {low }}$ and $A D A R^{\text {high }}$ patients stratified by $D H X 58$ levels in bladder cancer (BLCA; $n=407)$, breast cancer (BRCA; $n=1099$ ) and sarcoma (SARC; n=263) TCGA datasets. Median cut-offs were used for patient stratification and logrank test P values are shown. B) CAL27 cells transduced with doxycycline-inducible shRNAs targeting ADAR1 or GFP (negative control) were treated with doxycycline and transfected with two independent siRNAs targeting LGP2 (siLGP2 \#1 or \#2) or a control siRNA (siCtrl). 120h postextracted from stained cells and the dye intensity was quantified using a colorimetric assay $\left(O D_{590}\right) . \mathrm{OD}_{590}$ values of doxycycline-treated cells were normalized to the $\mathrm{OD}_{590}$ values of untreated cells. Quantification data of a representative experiment are shown $(n=2)$. 
siRNAs. Cells were harvested $72 \mathrm{~h}$ post-transfection and the type I IFN response was

analyzed by RT-qPCR analysis of IFN- $\beta$, IFIT1, and ISG15 transcript expression, normalized to

ACTB. Data from a representative experiment are shown with mean \pm s.d. $(n=2)$. B) LIM1215

cells were treated with or without 300 nM 5-AZA-CdR for 2 days and subsequently washed and transfected with the indicated siRNAs. Cells were harvested $72 \mathrm{~h}$ post-transfection and nM palbociclib or a DMSO control for 7 days. Three days after treatment initiation, cells were transfected with the indicated siRNAs and cultured for an additional $72 \mathrm{~h}$. The type I IFN response was monitored as in (C) $(n=2)$.

800

\section{Supplemental Figure 1, related to Figure 1: LGP2 is required for the induction of a type I}

IFN response upon siRNA-mediated depletion of ADAR1 in HEK293. A) Expression level and

type I IFN-inducibility of relevant proteins in HEK293 and THP-1. HEK293 and PMA-

differentiated THP-1 cells were treated with or without recombinant type I IFN. Protein

lysates were analyzed by SDS-PAGE followed by immunoblotting with the indicated monitored by RT-qPCR analysis (using Taqman probes) and normalized to ACTB. Data from 


\section{Supplemental Figure 2, related to Figure 1: LGP2-deficient cells fail to sense unedited self}

RNAs, yet maintain the ability to detect viral dsRNAs. A) LGP2-knockout HEK293 cells was used to monitor IFN- $\beta$ and IFIT1 expression and ADAR1 knockdown. All transcripts were normalized to ACTB. Data from a representative experiment is shown with mean \pm s.d. $(n=2)$. D) Cells were treated as in (C). Protein lysates were prepared 80h post siRNA transfection, followed by SDS-PAGE and immunoblotting using the indicated antibodies (n=2). E and F) LGP2-knockout HEK293 cells (clones 1 and 2) were transfected with 

representative experiment is shown with mean \pm s.d. $(n=2)$.

Supplemental Figure 3, related to Figure 2: A type I IFN response is unleashed in ADAR1 co-transfected with an empty vector (EV) or a FLAG-LGP2-encoding vector (LGP2) combined experiment are shown with mean \pm s.d. $(n=3)$. B) ADAR1-knockout HEK293 cells (clone 2) immunoblotting using the indicated antibodies $(n=3)$.

852 $A D A R^{\text {low }}$ (left panel) and $A D A R^{\text {high }}$ (right panel) patients from 17 TCGA datasets (sarcoma = SARC, liver = LIHC, esophageal $=$ ESCA, breast $=$ BRCA, bladder $=$ BLCA, endometrial $=$ UCEC, rectal $=$ READ, cervical $=$ CESC, melanoma $=S K C M$, ovarian $=O V$, pancreas $=$ PAAD, lung adenocarcinoma $=$ LUAD, stomach $=S T A D$, head and neck $=$ HNSC, clear cell renal cell carcinoma $=$ KIRC, lung squamous $=$ LUSC, colon $=$ COAD). Median cut-off values for both 
bioRxiv preprint doi: https://doi.org/10.1101/2021.10.27.465188; this version posted October 28,2021 . The copyright holder for this preprint (which was not certified by peer review) is the author/funder, who has granted bioRxiv a license to display the preprint in perpetuity. It is made available under aCC-BY-NC-ND 4.0 International license.

Supplemental Figure 5, related to Figure 5 and 6: Type I IFN responsiveness and siADAR1and type I IFN inducibility of relevant proteins in HT29, LIM1215, and CAL27 cells. Cells were treated with or without recombinant type I IFN. Protein lysates were analyzed by SDS-PAGE followed by immunoblotting with the indicated antibodies. B) Knockdown efficiency of ADAR1 and LGP2 upon doxycycline treatment or siRNA transfection, respectively. ADAR1 and LGP2 (DHX58) transcript levels were measured by RT-qPCR and plotted as mean \pm s.d. C) HT29 cells were transfected with the indicated siRNAs. Cells were harvested $72 \mathrm{~h}$ post-

871 transfection and RT-qPCR analysis was used to monitor the type I IFN response (IFN- $\beta$, IFIT1, 872 and ISG15 transcripts) and knockdown efficiency of ADAR1 and LGP2 (DHX58). All transcripts 873 were normalized to ACTB. Data from a representative experiment are shown with mean \pm 874 s.d. (n=2). D) LIM1215 cells were transfected with the indicated siRNAs. Cells were 875 harvested $72 \mathrm{~h}$ post-transfection and knockdown efficiency of ADAR1 and LGP2 (DHX58) was analyzed as in (C) $(n=2)$. 
bioRxiv preprint doi: https://doi.org/10.1101/2021.10.27.465188; this version posted October 28, 2021. The copyright holder for this preprint (which was not certified by peer review) is the author/funder, who has granted bioRxiv a license to display the preprint in perpetuity. It is made available under aCC-BY-NC-ND 4.0 International license. 
A

A $\quad \frac{\begin{array}{c}\text { THP-1 } \\ \text { WT }\end{array}}{\text { clone }} \frac{\Delta \text { RIG-I }}{1} \frac{2}{3} \frac{\Delta \text { MDA5 }}{3} \frac{\Delta \text { LGP2 }}{5 \quad 6}$

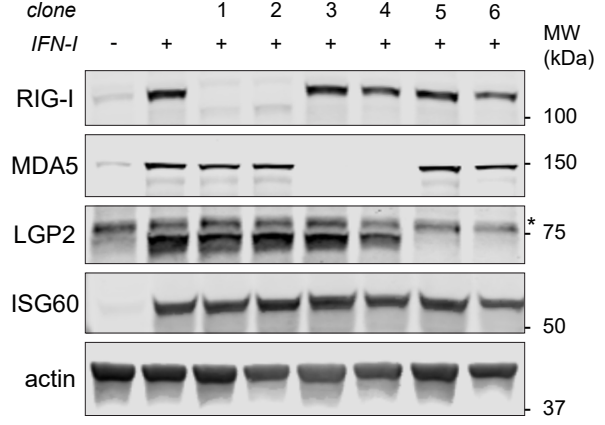

B
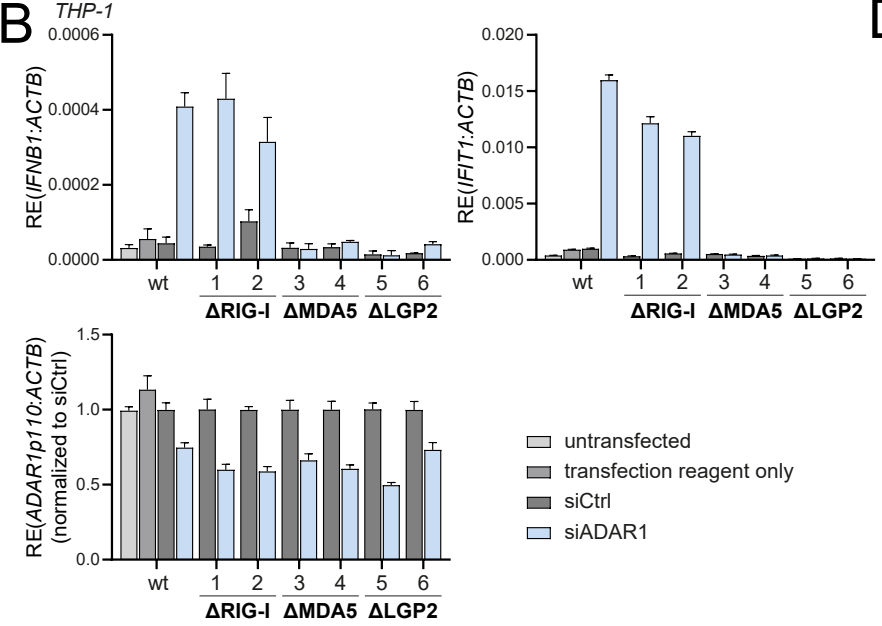

E

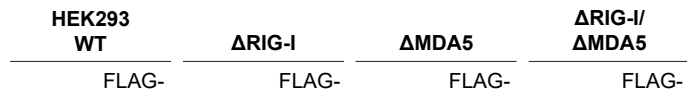
EV LGP2 EV LGP2 EV LGP2 EV LGP2

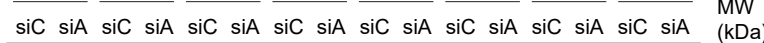

ADAR

ISG60

FLAG

p-IRF3

IRF3

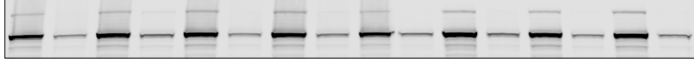

p-STAT1

STAT1

actin

$\square$ untransfected

$\square$ transfection reagent only

$\square$ siCtrl

$\square$ SiADAR1
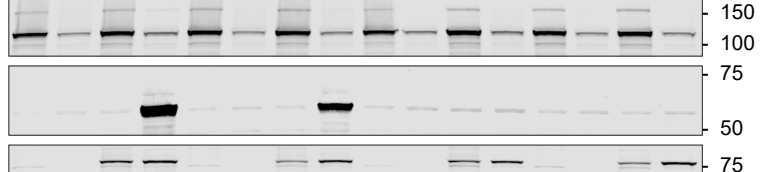

75
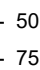

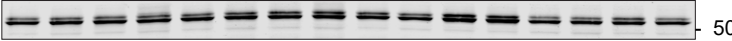

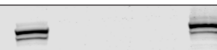

$=$ $-75$

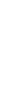

C

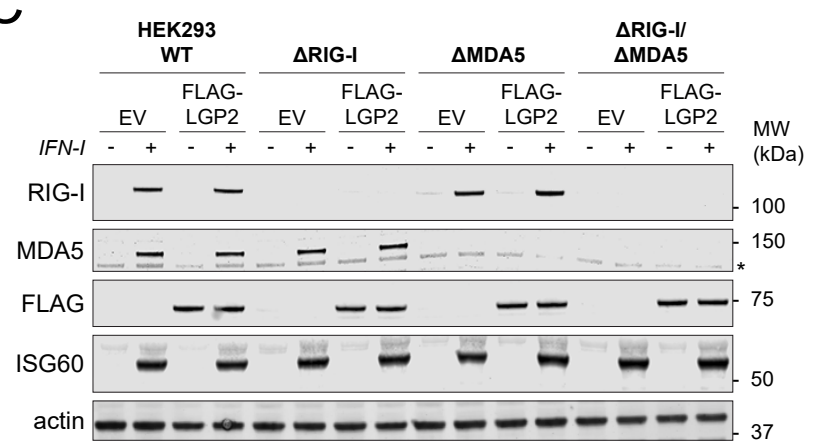

D
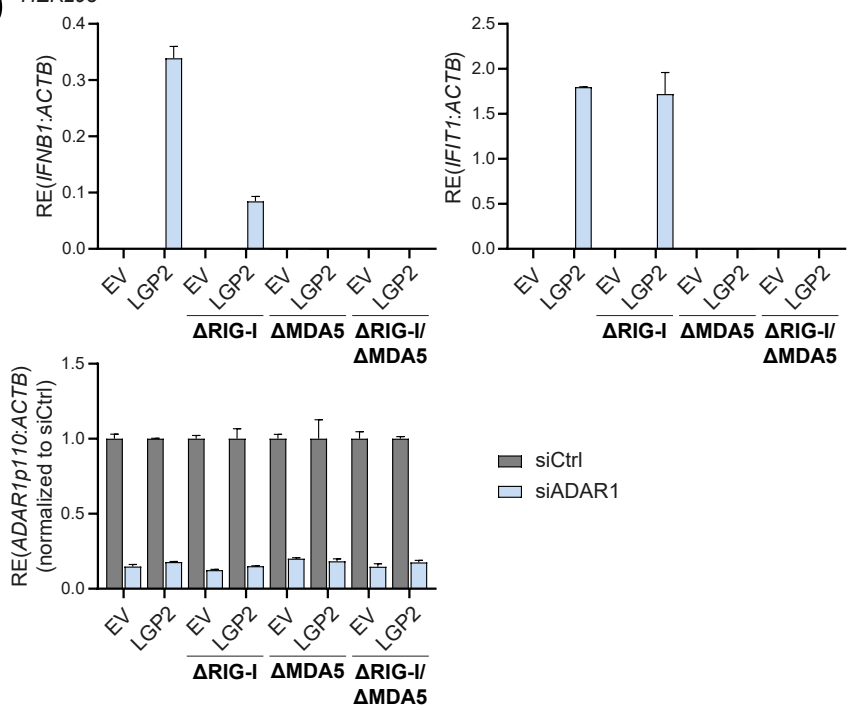

F
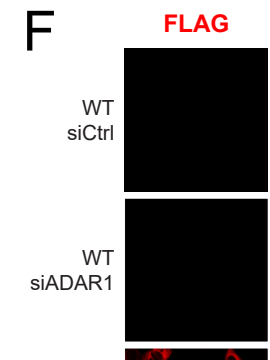

FLAG-LGP2
siCtr
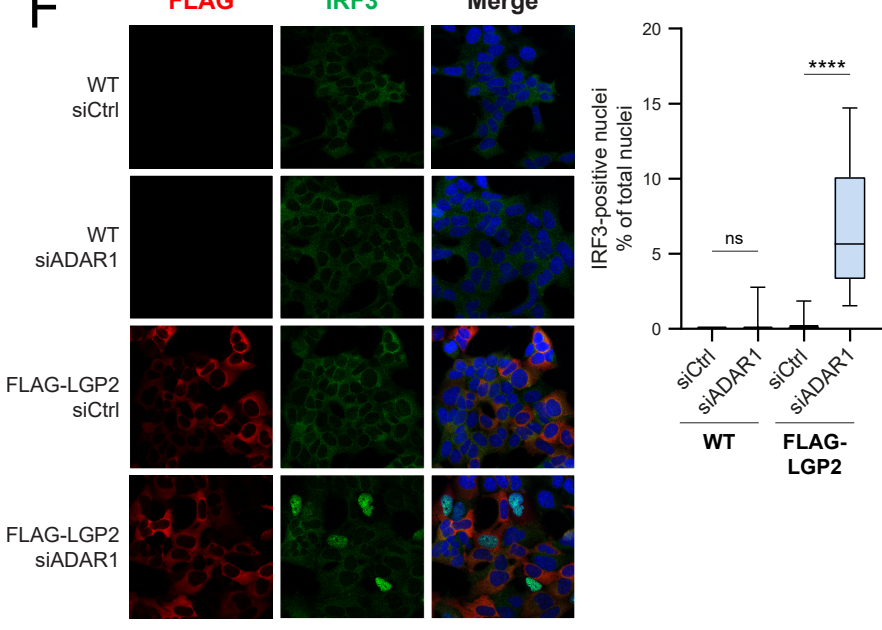
A $\quad \underset{\text { HEK293 }}{\mathrm{WT}}$

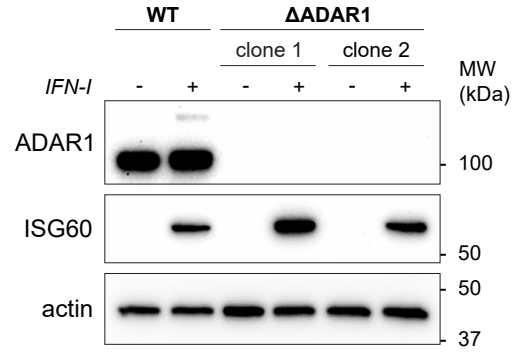

\section{$\triangle$ ADAR1 clone 1}

B

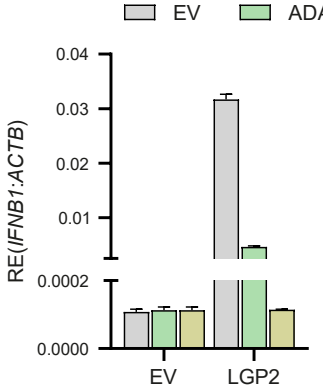

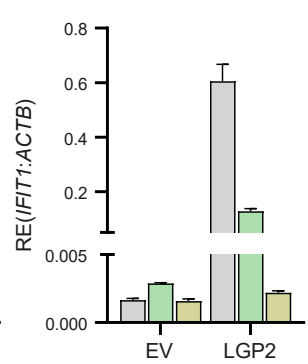

$\triangle$ ADAR1 clone 1

C

EV FLAG-LGP2

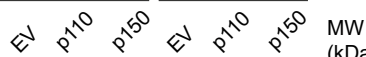

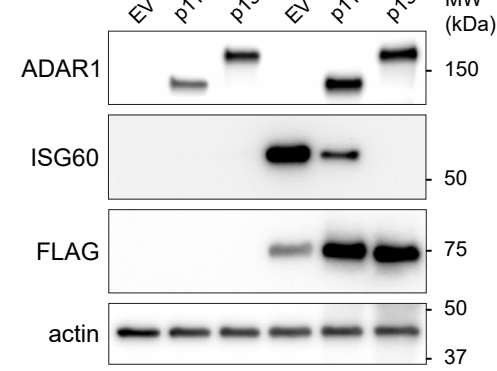




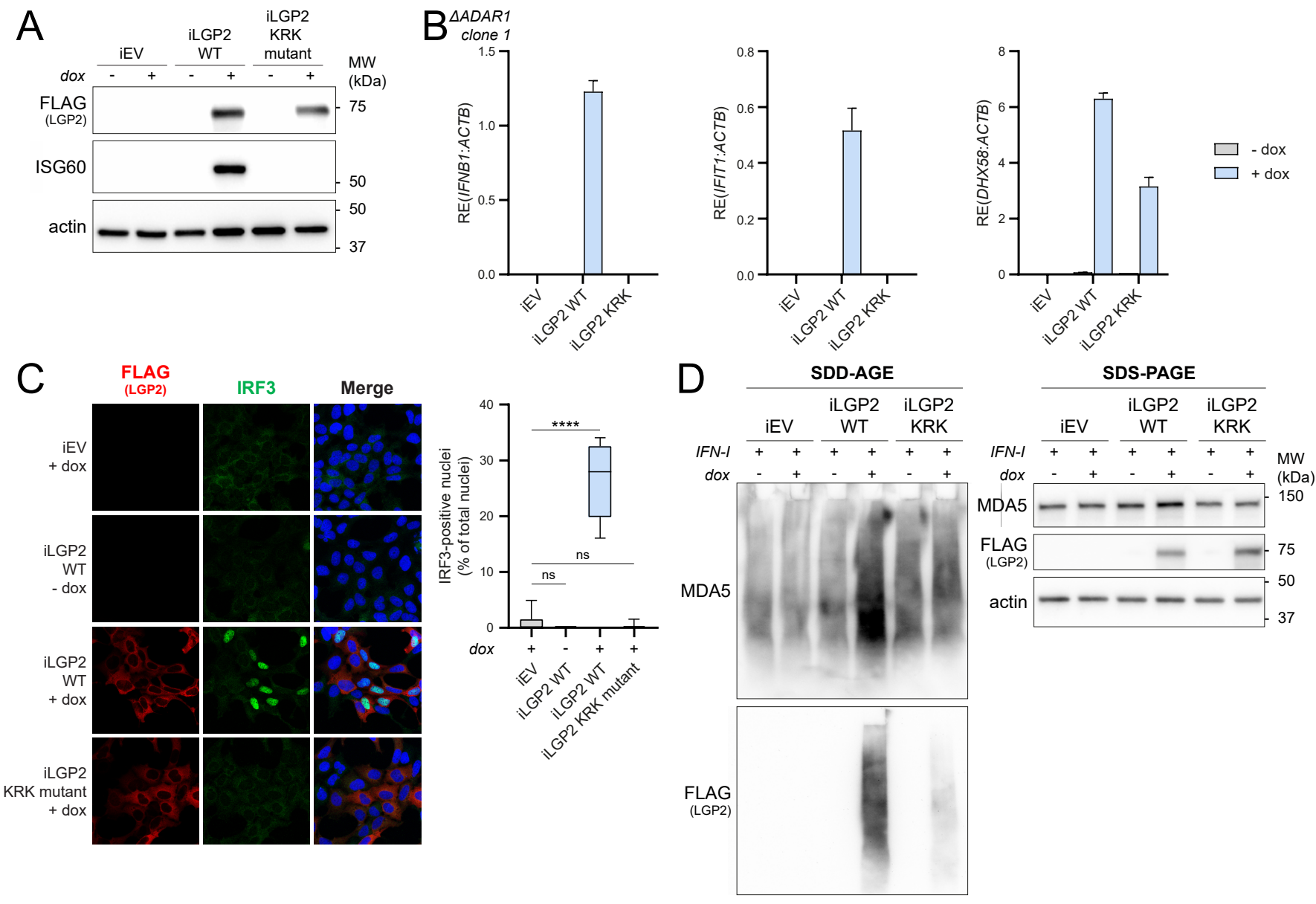


A

DExH/D helicase core

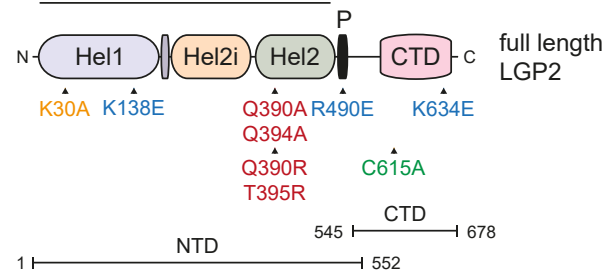

RNA binding mutants (single or combined point mutation(s)) ATPase mutant

$\square$ PACT-binding mutant $/ \mathrm{Zn}^{2+}$ binding motif mutant TRIM14-binding mutants
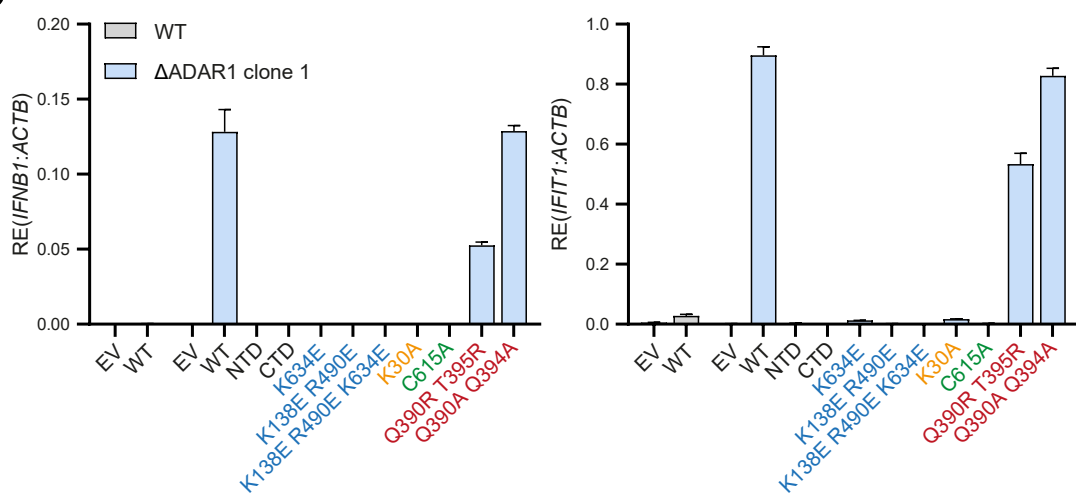

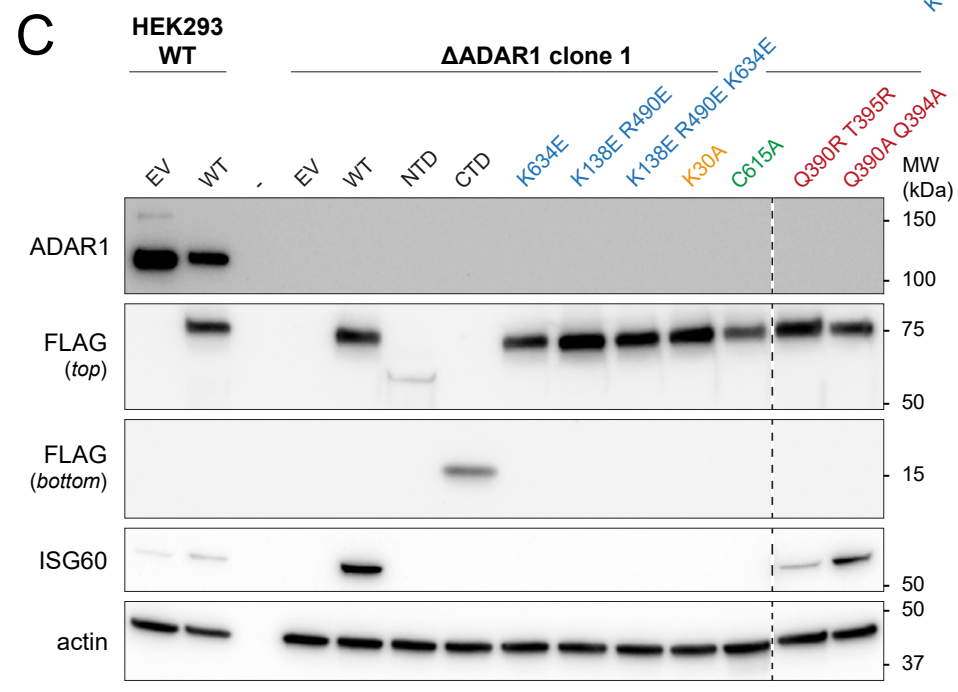



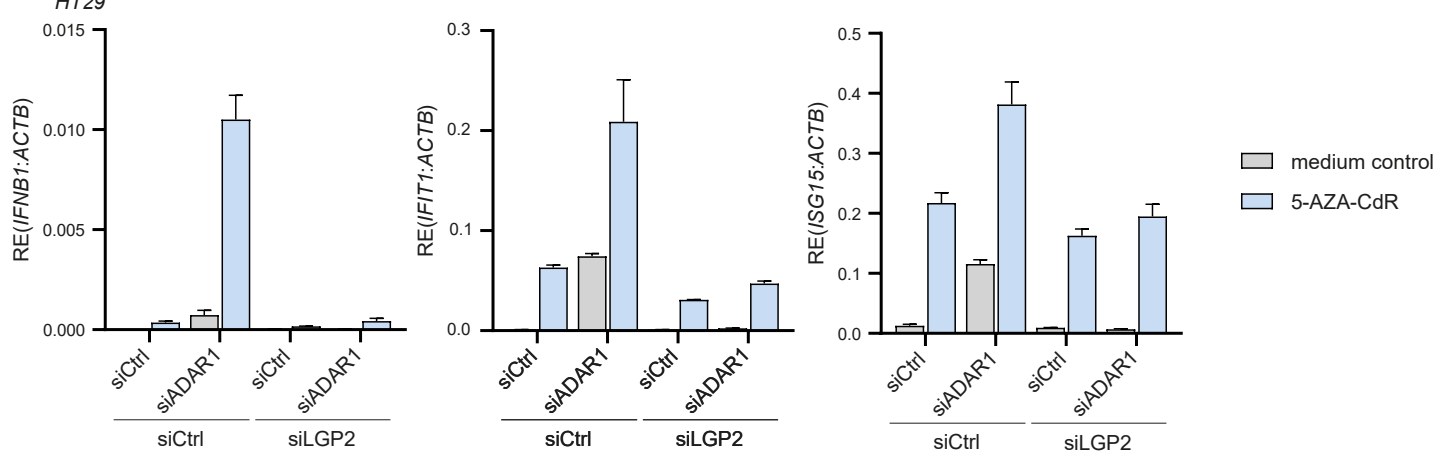

B
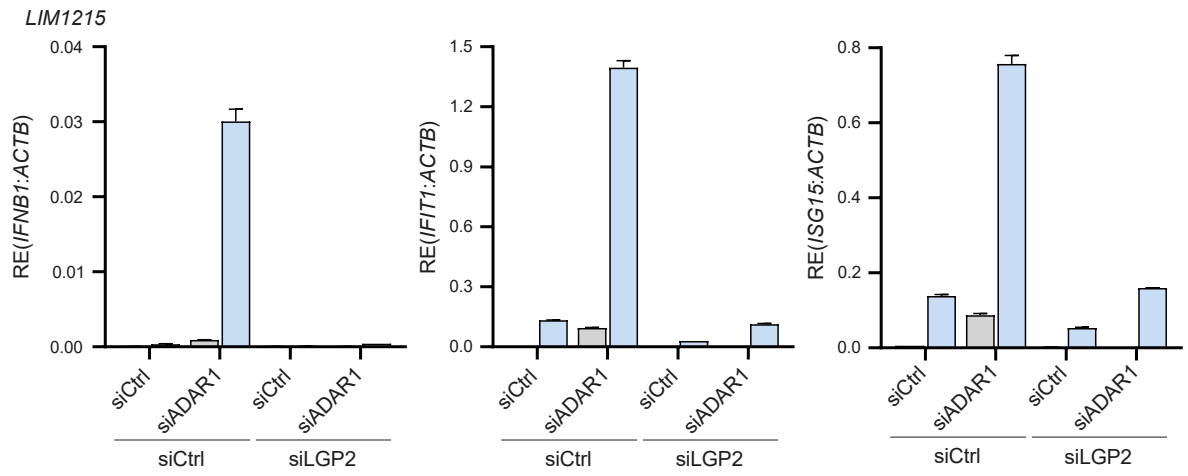

C
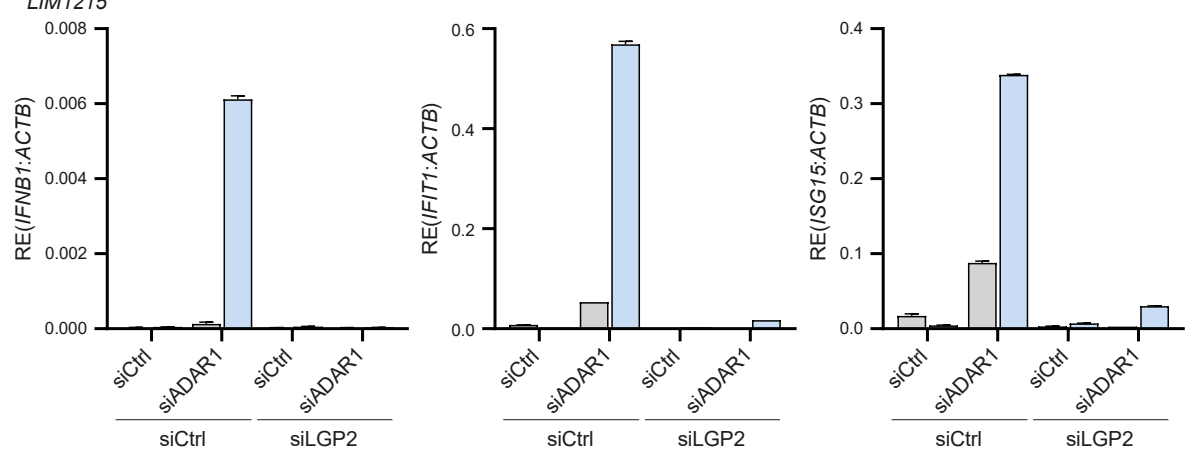

$\square$ medium control

5-AZA-CdR 


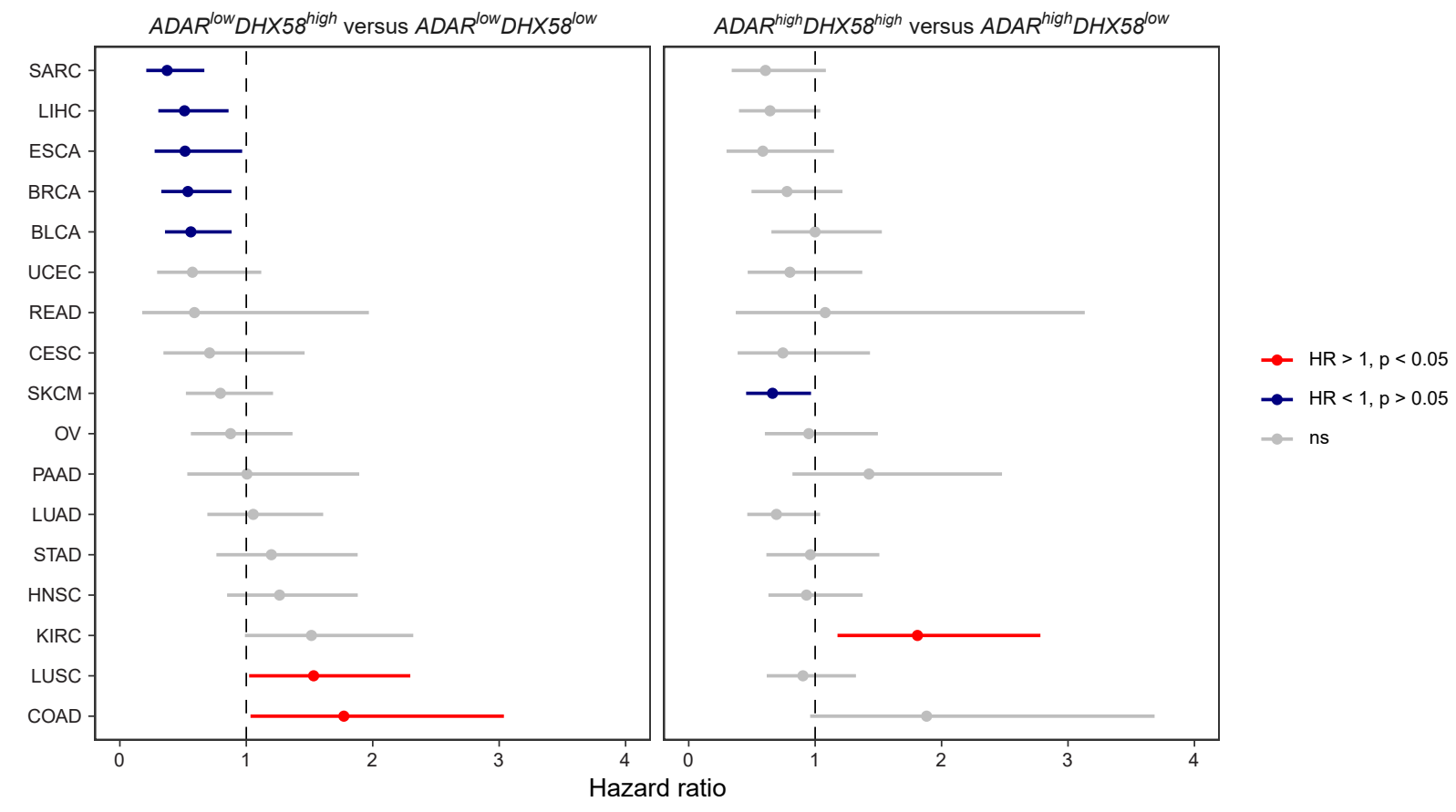




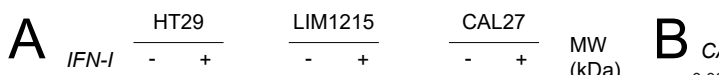

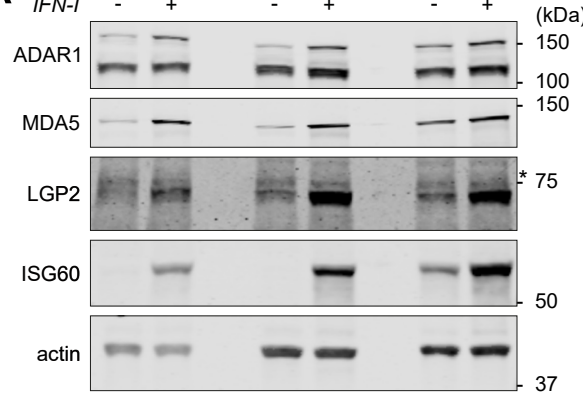

C

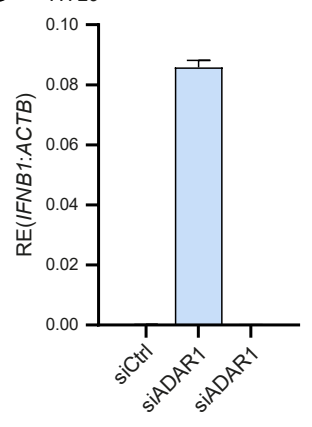

D
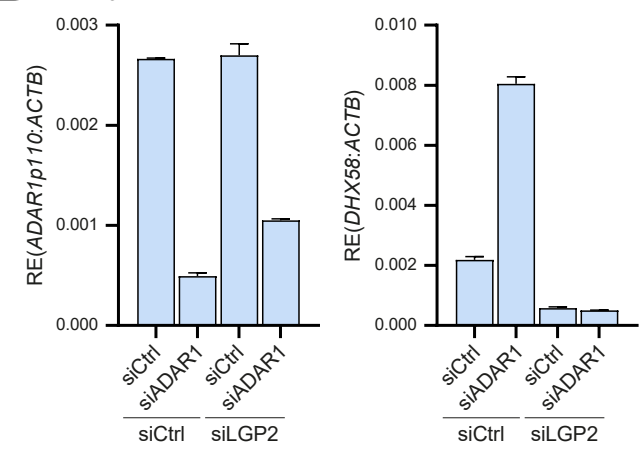
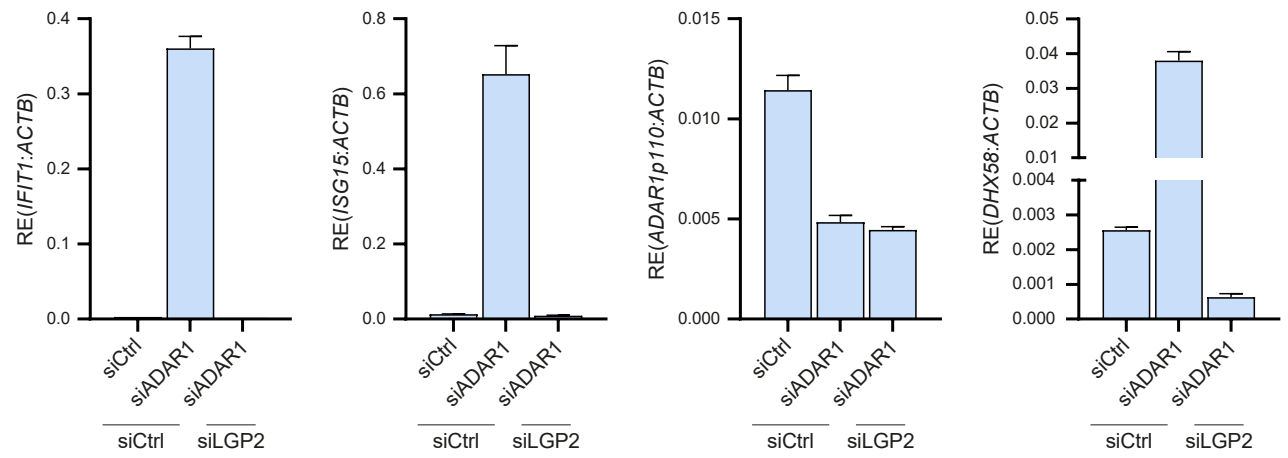

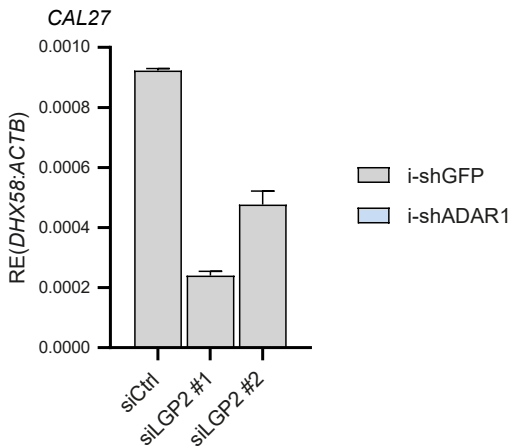

